\title{
Cardiac surgery late after heart transplantation: A safe and effective treatment option
}

Heidi Goerler, MD, Andre Simon, MD, Gregor Warnecke, MD, Anna L. Meyer, MD, Christian Kuehn, MD, Axel Haverich, MD, PhD, and Martin Strueber, MD

Objective: Owing to the improved long-term outcome after cardiac transplantation, cardiac allograft vasculopathy or valvular disease is developing late after heart transplantation in a growing number of patients. In this study, we evaluated our results of nonretransplant cardiac surgery in these patients and compared them with those after retransplantation.

Methods: Since 1983, a total of 867 heart transplantations have been performed at our institution. Among them, 44 patients underwent nonretransplant cardiac surgery, 4 of them repeatedly. The procedures included 19 coronary artery revascularizations, 20 tricuspid valve procedures, 4 other valvular procedures, 4 aortic operations, and 1 right atrial thrombectomy. Long-term results of these patients were compared with those of 20 patients after late cardiac retransplantation.

Results: Indications for nonretransplant surgery included cardiac allograft vasculopathy, tricuspid regurgitation, aortic and mitral valve insufficiency, as well as acute aortic dissection type A. Mean interval between heart transplantation and reoperation was 8.4 years. Mean follow-up was 5.8 years. Early mortality was $4.5 \%(2 / 44)$. The early deaths were caused by intracerebral bleeding and acute rejection. Actuarial survivals at 1, 5, and 7 years were $84 \%, 64 \%$, and $58 \%$, respectively. In comparison, early mortality in the retransplant group was $20 \%$ $(4 / 20)$ and survivals at the same time points were $70 \%, 70 \%$, and $47 \%$, respectively.

Conclusions: According to these results, we consider nonretransplant surgical options for cardiac allograft vasculopathy and valvular disease a safe and effective therapeutic approach with low early mortality and acceptable long-term results. (J Thorac Cardiovasc Surg 2010;140:433-9)

Heart transplantation (HTX) has become an established treatment option for end-stage heart failure and has been successfully performed for more than 30 years. Owing to the improvement of surgical techniques and immunosuppressive therapy, long-term survival has significantly improved during this time. ${ }^{1}$ Thus, an increasing number of patients have late morbidity after HTX, for example, cardiac allograft vasculopathy (CAV) and valvular disease.

To date, a limited number of reports, on small patient populations, have been published in the literature on the management of posttransplant cardiac disease.

Despite the growing knowledge regarding the pathogenesis of CAV, treatment options are still limited. ${ }^{2}$ Coronary angioplasty and coronary artery bypass grafting (CABG) are available therapeutic strategies. ${ }^{3-7}$ In tricuspid regurgitation (TR), which is the most common valvular heart disease after HTX, surgical correction can be performed. ${ }^{8-14}$ However,

\footnotetext{
From the Division of Cardiothoracic, Transplantation and Vascular Surgery, Hannover Medical School, Hannover, Germany.

Disclosures: None.

Received for publication Oct 6, 2009; revisions received Feb 1, 2010; accepted for publication Feb 14, 2010; available ahead of print April 12, 2010.

Address for reprints: Heidi Goerler, MD, Division of Cardiothoracic, Transplantation and Vascular Surgery, Hannover Medical School, Carl-Neuberg-Strasse 1, 30625

Hannover, Germany (E-mail: goerler.adelheid@mh-hannover.de). $0022-5223 / \$ 36.00$

Copyright (c) 2010 by The American Association for Thoracic Surgery doi:10.1016/j.jtcvs.2010.02.033
}

these treatment options are not applicable for all patients, especially those with severely impaired graft function. Thus, cardiac retransplantation remains the only definitive therapy for cardiac allograft failure of any etiology. Unfortunately, this therapeutic approach is limited by the scarcity of suitable donor organs and the associated short- and longterm mortality. ${ }^{15-17}$ To evaluate the available treatment options for long-term cardiac morbidity after HTX, we retrospectively analyzed our results after nonretransplant cardiac surgery in patients after HTX.

\section{PATIENTS AND METHODS \\ Patients}

Between July 1983 and December 2008, a total of 867 HTXs have been performed in 819 patients at our institution. Among them, 44 patients underwent nonretransplant cardiac operations late after HTX ( $>30$ days), 4 of which were repeated (Figure 1). The procedures included 19 coronary artery revascularizations, 20 tricuspid valve procedures, 4 other valvular procedures, 4 aortic operations, and 1 right atrial thrombectomy. Five patients received cardiac retransplantation late after cardiac reoperation. During the same period of time, 20 patients underwent cardiac retransplantation late after HTX. Patients who underwent retransplantation for acute graft failure, as well as patients with acute cardiac reoperation after HTX, were excluded from this study. Patient characteristics are summarized in Table 1.

\section{Preoperative Management}

Patients coming for surgical reintervention after HTX were thoroughly evaluated. Less-invasive interventional therapeutic options, such as percutaneous coronary angioplasty, were always considered before surgery was 


\section{Abbreviations and Acronyms

$\begin{aligned} & \text { CABG = coronary artery bypass grafting } \\ & \text { CAV = cardiac allograft vasculopathy } \\ & \text { HTX }=\text { heart transplantation } \\ & \text { MIDCAB = } \text { minimally invasive direct coronary } \\ & \text { artery bypass grafting } \\ & \text { OPCAB = } \text { off-pump coronary artery bypass } \\ & \text { grafting } \\ & \text { TR } \text { tricuspid regurgitation }\end{aligned}$

performed. All patients received preoperative computed tomographic scans to define the distance between the heart and sternum. Calcineurin inhibitors were discontinued at the time of admission for reduction of nephrotoxicity.

\section{Immunosuppression and Follow-up}

Immunosuppression consisted of a triple maintenance therapy based on cyclosporine or tacrolimus, in combination with azathioprine or, more recently, mycophenolate mofetil and steroids. All patients receive steroids for life. All patients were followed up at our outpatient clinic. Myocardial biopsy specimens were routinely obtained during the first year or, more recently, during the first 6 months. Routine catheterization was performed during the first year after transplantation and, depending on the coronary status, every second or third year thereafter.

\section{Statistical Methods}

Data were prospectively recorded and retrospectively analyzed. Continuous variables were presented as mean \pm standard deviation and compared with the independent sample $t$ test. Categorical variables were presented as proportions and compared by $\chi^{2}$ analysis. Actuarial survival was estimated with the Kaplan-Meier method and analyzed by the log-rank test. All data were analyzed with the Statistical Program of Social Sciences (SPSS, version 16.0; SPSS, Inc, Chicago, Ill).

\section{RESULTS \\ Patient Population}

A total of 48 cardiac reoperations after HTX were performed in 44 patients. Four patients underwent repeated (2) surgical procedures. Five patients received a second HTX late after cardiac reoperation (1-4 years postoperatively) (Figure 1). Mean age was $51.5 \pm 12.5$ years (range, 20-70 years). Thirty-three $(75 \%)$ patients were male and $11(25 \%)$ female. Mean interval between transplantation and reoperation was $8.4 \pm 5.0$ years (range, 32 days-21 years). Mean duration of surgery was $223 \pm 68$ minutes (Table 1). Mean follow-up was $5.8 \pm 4.7$ years (range, 19 days-17 years) with a cumulative follow-up of 256 patient-years.

For comparison, patient characteristics of the 20 patients who underwent late cardiac retransplantation are presented in Table 1.

\section{Underlying Diagnoses and Surgical Procedures}

Indications for surgery included coronary artery disease, valvular disease, as well as acute aortic dissection type A. Surgical procedures are listed in Table 1.
CABG. Seventeen patients were operated on for coronary artery disease, among them 14 patients with CAV and 4 patients with pre-existing coronary artery disease of the graft. These patients underwent a total of 19 coronary artery revascularizations, either as complete arterial revascularization (14 procedures) or with a combination of arterial and venous grafts (5 procedures). Six operations were performed offpump, among them 2 minimally invasive direct coronary artery bypass grafting (MIDCAB) procedures and 4 off-pump coronary artery bypass grafting (OPCAB) procedures. All 17 patients received a left internal thoracic artery bypass graft. The right thoracic artery was chosen twice and the radial artery was used in 9 patients, in 7 of them as a T graft and in 2 as a free graft. One procedure was an emergency procedure after acute myocardial infarction and 1 was performed as an urgent procedure 2 weeks after myocardial infarction. Mean interval between HTX and CABG operation was $9.0 \pm 5.5$ years. Two patients received repeated coronary revascularizations at 1 week and 1 year after the first operation, respectively. Two patients underwent late retransplantation at 1 and 4 years, postoperatively.

Tricuspid valve surgery. Nineteen patients had severe TR. Four of them received tricuspid valve repair and 15 were treated with biological tricuspid valve replacement, 1 of them repeatedly ( 4 years after the first replacement because of structural valve deterioration). In 2 patients, an additional CABG operation was performed because of concomitant coronary artery disease. Two patients underwent late retransplantation at 17 and 20 months, postoperatively. The mean interval between HTX and tricuspid valve surgery was $8.6 \pm 4.2$ years.

Valvular procedures. Four patients had different valvular pathologic conditions. Among them, 1 patient had aortic, mitral, and tricuspid valve endocarditis. This patient received combined aortic, mitral, and tricuspid valve replacement. Another patient had aortic valve insufficiency 5 years after valve-sparing aortic root replacement, which was initially performed for acute aortic dissection type A (see below). The patient underwent aortic valve replacement. (This patient received a second HTX 2 years later and is still alive). The third patient underwent mitral valve replacement for isolated mitral valve insufficiency. The remaining patient underwent combined mitral and tricuspid valve repair for severe regurgitation. The mean interval between HTX and valve surgery was $12.3 \pm 7.2$ years.

Aortic surgery. Three patients had acute aortic dissection type $\mathrm{A}$ at 1 month, 3 years, and 9 years after transplantation. In all 3 patients, the dissection was limited to the donor part of the aorta. Valve-sparing aortic root replacement, as described by David and Feindel, ${ }^{18}$ has been performed in 2 cases, whereas in 1 case, the aortic root had to be replaced because of significant aortic valve regurgitation. Two patients received an additional venous bypass graft to the right 


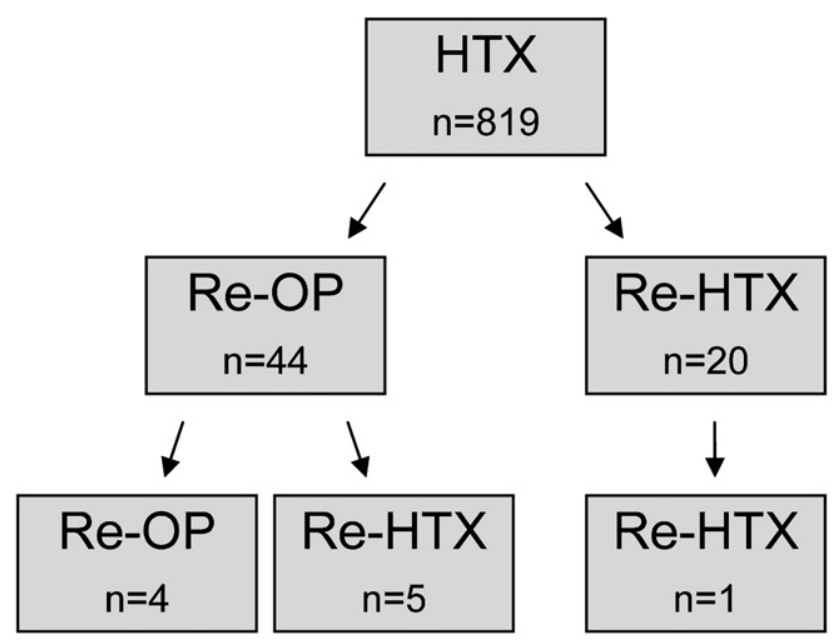

FIGURE 1. Cumulative survival after late cardiac reoperation and retransplantation after HTX. Re-OP, Reoperation; Re-HTX, retransplantation.

coronary artery because of dissection of the right coronary ostium. One patient had severe aortic valve regurgitation 5 years after the David operation and underwent aortic valve replacement (see above). The same patient received cardiac retransplantation another 2 years later for CAV. One patient with Marfan syndrome had chronic dissection of the aortic arch and descending aorta owing to acute aortic dissection type A before HTX. This patient underwent aortic arch replacement. Mean interval between HTX and aortic surgery was $4.2 \pm 3.8$ years.

Others. One patient underwent right atrial thrombectomy 3 years after transplant. This patient is currently alive at year 18 after transplantation.

\section{Survival}

Early mortality ( $\leq 30$ days) was $4.5 \%(2 / 44)$ in the nonretransplant group. Twenty patients died late ( $>30$ days) after surgery. The 2 early deaths were caused by intracerebral bleeding in 1 patient, after triple valve replacement for acute endocarditis, and by acute rejection in the other patient after tricuspid valve repair. In the CABG group, 9 patients died late after repeated surgery. Ten patients died late after tricuspid valve replacement and 1 died late after combined tricuspid and mitral valve repair. All patients receiving surgery for aortic dissection are still living. Two of the 5 patients who underwent cardiac retransplantation after nontransplant surgery died late after retransplantation.

Causes of late deaths were acute rejection, chronic graft failure (CAV and biventricular heart failure), apoplexy, malignancies (lymphoma and leukemia), and others, including mesenterial infarction, cardiac arrhythmias resulting from electrolyte imbalance, septic cerebral embolism, and sudden deaths of unknown origin. Overall causes of deaths are listed in Table 1. Actuarial survivals at 1, 3, 5, and 7 years were $84 \%, 72 \%, 64 \%$, and $58 \%$, respectively. In comparison, early mortality in the retransplant group was $20.0 \%(4 / 20)$ and survivals at the same time points were $70 \%, 70 \%$, $70 \%$, and $47 \%$, respectively (Figure 2 ).

\section{Risk Factor Analysis}

For the identification of risk factors for mortality, patient characteristics, as well as procedure-associated data, have been used in both univariate and multivariate analyses (Table 1). However, none of the included variables was identified as a risk factor for mortality.

\section{DISCUSSION}

This study summarizes our experience with cardiac reoperation of patients late after HTX. To our knowledge, this is the largest cohort of patients in literature. As described above, long-term survival after HTX has significantly improved. ${ }^{1}$ As a consequence, an increasing number of patients have recurrent cardiac disease late after HTX. At the same time, the number of available donor organs is constantly decreasing. Therefore, the indication for a retransplantation has to be carefully evaluated and alternative therapeutic approaches investigated. ${ }^{15,16}$

According to our results, nonretransplant cardiac surgery can be performed with low perioperative mortality. There were 2 early deaths in our patient cohort. One patient had endocarditis and received a triple valve replacement-an operation that is associated with a high operative risk per se. The other died early after tricuspid valve repair, which was performed 2 months after the original transplantation owing to severe TR, indicating a pre-existing organ dysfunction. The favorable short- and long-term outcomes support the decision for organ-sparing cardiac surgery as the first-line therapeutic approach in patients with recurrent cardiac disease late after HTX.

However, the indications for cardiac retransplantation and organ-sparing surgery are different and cardiac reoperation is not an option for all patients, especially those with severely impaired graft function. Therefore, careful selection of the therapeutic approach is required for each individual patient.

According to our experience the following aspects have to be considered for favorable short-and long-term outcomes after performing cardiac surgery in HTX recipients.

\section{Management of Surgical and Patient-Associated Risks}

Cardiac surgery in patients after HTX is associated with a combination of specific risks. Among them are an increased risk of intraoperative and postoperative bleeding owing to (more or less severe) adhesions after previous surgical procedures, as well as an increased risk of renal failure, infection, and wound healing disorders owing to long-term immunosuppression. To minimize the risk of resternotomy, we performed a computed tomographic scan in every patient before the operation. The decision for the cannulation site 
TABLE 1. Patient characteristics

\begin{tabular}{|c|c|c|c|}
\hline & $\begin{array}{c}\text { Reoperation } \\
\text { after HTX }\end{array}$ & Retransplantation & $\begin{array}{c}P \\
\text { i value }\end{array}$ \\
\hline Patients (n) & 44 & 20 & \\
\hline Procedures (n) & 48 & 21 & \\
\hline $\begin{array}{l}\text { Mean age at the time } \\
\text { of surgery (y) }\end{array}$ & $\begin{array}{l}51.5 \pm 12.5 \\
\quad(\text { range } 20-70)\end{array}$ & $\begin{array}{l}50.5 \pm 10.4 \\
\quad(21-67)\end{array}$ & NS \\
\hline \multicolumn{4}{|l|}{ Gender } \\
\hline Male & $33(75 \%)$ & $18(90 \%)$ & NS \\
\hline Female & $11(25 \%)$ & $2(10 \%)$ & \\
\hline $\begin{array}{c}\text { Interval between HTX and } \\
\text { reoperation/re-TX (y) }\end{array}$ & $\begin{array}{l}8.4 \pm 5.0 \\
(0.1-21.0)\end{array}$ & $\begin{array}{l}7.0 \pm 5.2 \\
(0.2-17.1)\end{array}$ & NS \\
\hline Surgical procedures & 48 & 21 & \\
\hline CABG & 19 & & \\
\hline Arterial grafts & 14 & & \\
\hline $\begin{array}{l}\text { Arterial and venous } \\
\text { grafts }\end{array}$ & 5 & & \\
\hline TV surgery & 20 & & \\
\hline TV repair & 4 & & \\
\hline TVR & 14 & & \\
\hline $\mathrm{TVR}+\mathrm{CABG}$ & 2 & & \\
\hline Other valvular procedures & 4 & & \\
\hline AVR & 1 & & \\
\hline MVR & 1 & & \\
\hline $\mathrm{AVR}+\mathrm{MVR}+\mathrm{TVR}$ & 1 & & \\
\hline MV + TV repair & 1 & & \\
\hline Aortic surgery & 4 & & \\
\hline $\begin{array}{l}\text { Acute aortic diss. } \\
\text { type A }\end{array}$ & 3 & & \\
\hline $\begin{array}{l}\text { Chronic aortic diss. } \\
\text { type A }\end{array}$ & 1 & & \\
\hline Other & 1 & & \\
\hline $\begin{array}{l}\text { Right atrial } \\
\text { thrombectomy }\end{array}$ & 1 & & \\
\hline Re-HTX & $\left(5^{*}\right)$ & 20 & \\
\hline Re-re-HTX & & 1 & \\
\hline Operation time (min) & $\begin{array}{l}223 \pm 68 \\
\quad(65-398)\end{array}$ & $\begin{array}{l}250 \pm 97 \\
\quad(145-540)\end{array}$ & NS \\
\hline Thirty-day mortality & $2(4.5 \%)$ & $4(20.0 \%)$ & .049 \\
\hline Overall mortality & $22(50 \%)$ & $11(55 \%)$ & NS \\
\hline \multicolumn{4}{|l|}{ Causes of death } \\
\hline Acute rejection & $2(4.5 \%)$ & $3(15.0 \%)$ & \\
\hline Initial graft failure & 0 & $2(10.0 \%)$ & \\
\hline Chronic graft failure & $2(4.5 \%)$ & $1(5.0 \%)$ & \\
\hline Infection & 0 & $1(5.0 \%)$ & \\
\hline Liver failure & 0 & $2(10.0 \%)$ & \\
\hline Cerebral & $2(4.5 \%)$ & $1(5.0 \%)$ & \\
\hline Malignancy & $3(6.8 \%)$ & 0 & \\
\hline Other & $6(13.6 \%)$ & $1(5.0 \%)$ & \\
\hline Unknown & $7(15.9 \%)$ & 0 & \\
\hline
\end{tabular}

HTX, Heart transplantation; $T X$, transplantation; $C A B G$, coronary artery bypass grafting; $T V$, tricuspid valve; $T V R$, tricuspid valve replacement; $A V R$, aortic valve replacement; $M V R$, mitral valve replacement; $M V$, mitral valve; $N S$, not significant. *Not included in retransplant calculations.

was based on the distance between the heart and sternum. In our study group, femoral cannulation was chosen only once in a patient with acute aortic dissection type A. Alternatively,

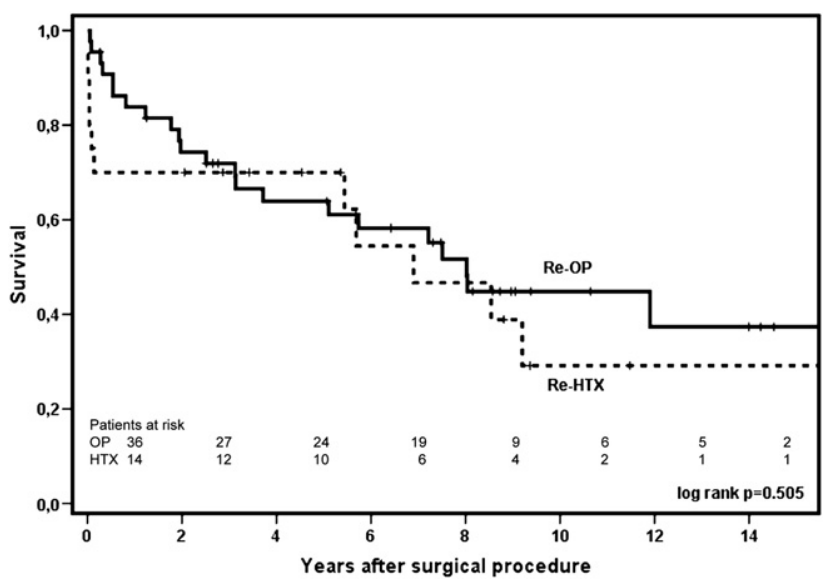

FIGURE 2. Cardiac surgery after HTX: Number of patients who underwent cardiac reoperations and retransplantations late ( $>30$ days) after primary heart transplantation between July 1983 and December 2008. HTX, Heart transplantation; $R e-O P$, reoperation; $R e-H T X$, retransplantation.

a lateral approach might be favorable, either as a MIDCAB procedure from the left side or as right-sided thoracotomy for tricuspid or mitral valve surgery. Among our patients, this approach has been successfully applied in 4 patients, 2 with MIDCAB procedures and 2 with tricuspid valve replacement. Owing to the impaired renal function of the majority of patients late after HTX, calcineurin inhibitors were discontinued in all patients at the time of admission. Postoperatively, oral immunosuppression was preferred to intravenous application whenever possible. If technically feasible, off-pump procedures were chosen. When cardiopulmonary bypass was required, pulsatile pump flow was preferred. ${ }^{19}$

\section{CABG Surgery}

In the majority of our study population, listed in Table 2, coronary artery disease was diagnosed by routine catheterization inasmuch as typical symptoms, such as angina, were often missing. Two patients had a myocardial infarction, emphasizing the importance of routine catheterization after HTX. The first catheterization after HTX is especially important to identify the coronary status of the allograft. In our study group, 4 patients had relevant coronary artery stenosis of the graft, which was successfully treated by CABG operation. To date, 3 of them are still alive. With respect to surgical technique, we prefer arterial bypass grafts in these patients because of the favorable long-term patency rates and technical advantages in MIDCAB and OPCAB procedures (the aorta is not touched). ${ }^{20}$ Another reason for the choice of arterial grafts was the lack of sufficient vein graft material after previous CABG operations (3 patients).

Thus far, only few reports have been published about coronary artery revascularization after HTX, summarized in Table 3. Musci and associates ${ }^{5}$ reported on 7 patients with CABG surgery after HTX; among them, 4 required emergency procedures. They concluded that it depended on the 
TABLE 2. CABG surgery after HTX

\begin{tabular}{|c|c|c|c|c|c|c|c|c|c|}
\hline No. & $\begin{array}{c}\text { Previous } \\
\text { interventions }\end{array}$ & $\begin{array}{l}\text { Catheter } \\
\text { indication }\end{array}$ & Lesion type & $\mathbf{E F}$ & No. of grafts $A V$ & $\begin{array}{c}\text { Surgical } \\
\text { access }\end{array}$ & Reintervention & Reoperation & $\begin{array}{l}\text { Surviva } \\
\text { (d) }\end{array}$ \\
\hline 1 & None & Routine & $\begin{array}{l}\text { C/LMCA (CAD of } \\
\text { the graft) }\end{array}$ & Normal & LITA (1) & OPCAB & None & None & 196 \\
\hline 2 & None & $\begin{array}{l}\text { Angina/ } \\
\text { infarction }\end{array}$ & $\mathrm{B} / \mathrm{C}$ & Slightly reduced & LITA (1), VG (2) & Standard & None & None & 2928 \\
\hline 3 & None & Routine & $\mathrm{B} / \mathrm{C}$ & Slightly reduced & LITA (1), RA (2) & Standard & None & None & 967 \\
\hline 4 & $2 \times \mathrm{PCI}$ & Routine & $\mathrm{A} / \mathrm{C} / \mathrm{LMCA}$ & Severely reduced & LITA (1), RA (1) & Standard & None & Re-TX & 2975 \\
\hline 5 & None & Routine & $\begin{array}{l}\mathrm{C} \text { (CAD of the } \\
\text { graft) }\end{array}$ & Normal & LITA (2) & OPCAB & None & None & 2669 \\
\hline 6 & $1 \times \mathrm{PCI}$ & $\begin{array}{l}\text { Limited physical } \\
\text { activity }\end{array}$ & $\mathrm{B} / \mathrm{C}$ & Medium reduced & LITA (1), RA (1) & Standard & None & None & 100 \\
\hline 7 & None & Routine & $\begin{array}{l}\text { A (CAD of the } \\
\text { graft) }\end{array}$ & Normal & $\begin{array}{l}\operatorname{LITA}(1), \text { RA (1) } \\
\quad(+ \text { TEA })\end{array}$ & Standard & $1 \times \mathrm{PCI}$ & None & 3305 \\
\hline 8 & $1 \times \mathrm{PCI}$ & Routine & $\mathrm{A} / \mathrm{B}$ & Normal & LITA (1), VG (1) & OPCAB & None & None & 3184 \\
\hline 9 & None & Routine & $\mathrm{B} / \mathrm{C}$ & Slightly reduced & LITA (1), VG (2) & Standard & $2 \times \mathrm{PCI}$ & None & 4343 \\
\hline 10 & $2 \times \mathrm{PCI}$ & Routine & C/LMCA & Normal & LITA (1) & MIDCAB & $3 \times \mathrm{PCI}$ & RITA (1), RA (1) & 2933 \\
\hline 11 & None & Routine & $\begin{array}{l}\text { B/C/LMCA (CAD } \\
\text { of the graft) }\end{array}$ & Normal & $\begin{array}{l}\text { LITA (1), RITA } \\
\quad(1), \text { RA (1) }\end{array}$ & Standard & None & None & 3423 \\
\hline 12 & None & Routine & $\mathrm{B} / \mathrm{C}$ & Normal & LITA (1), RA (1) & Standard & None & None & 3271 \\
\hline 13 & $1 \times \mathrm{PCI}$ & Routine & B & Normal & LITA (1) & OPCAB & None & None & 719 \\
\hline 14 & $2 \times \mathrm{PCI}$ & Routine & $\mathrm{B}$ & Medium reduced & LITA (1), RA (2) & Standard & None & None & 295 \\
\hline 15 & $6 \times \mathrm{PCI}$ & Routine & $\mathrm{B} / \mathrm{C} / \mathrm{LMCA}$ & Severely reduced & $\operatorname{LITA}(1), \operatorname{RA}(1)$ & Standard & None & RITA (1) & 1140 \\
\hline 16 & $1 \times \mathrm{PCI}$ & Routine & $\mathrm{C}$ & Slightly reduced & LITA (1) & MIDCAB & $1 \times \mathrm{PCI}$ & Re-TX & 2741 \\
\hline 17 & None & Routine & $\mathrm{A} / \mathrm{C} / \mathrm{LMCA}$ & Normal & LITA (1), VG (3) & Standard & None & None & 919 \\
\hline
\end{tabular}

$C A B G$, Coronary artery bypass grafting; $H T X$, heart transplantation; $E F$, ejection fraction; $A V$, arterial/venous; $L M C A$, left main coronary artery; $C A D$, coronary artery disease; $L I T A$, left internal thoracic artery; $O P C A B$, off-pump coronary artery bypass grafting; $V G$, vein graft; $R A$, radial artery; $P C I$, percutaneous coronary intervention; Re-TX, retransplantation; TEA, thromboendarterectomy; $M I D C A B$, minimally invasive direct coronary artery bypass grafting; RITA, right internal thoracic artery; $A, B$ and $C$, type A, B and $\mathrm{C}$ lesions.

morphologic characteristics of coronary lesions whether a patient could be successfully treated or not (type A lesions vs type $\mathrm{B}$ and $\mathrm{C}$ lesions). According to our experience, patients with CAV often have diffuse coronary artery sclerosis with a history of multiple stent implantations. These patients can be successfully treated by surgical revascularization (especially in case of additional left main stem stenosis) so long as suitable localizations for bypass grafts can be identified. Halle and coworkers ${ }^{3}$ presented outcome data of 12 patients after posttransplant CABG surgery. They remarked that owing to the low number of patients, the assessment of this procedure was still limited. Additionally, the mean followup of both studies was relatively short at 9 and 10 months, respectively. The largest number of patients after surgical revascularization after HTX has been published by Bhama and colleagues. ${ }^{7}$ They reported on 13 patients with a mean followup of 39 months. They concluded that CABG operation after HTX is a viable treatment option with good medium-term outcomes. Owing to the key role of CAV as the major cause of death after HTX and the major cause for retransplantation, ${ }^{1,2}$ further studies that provide long-term follow-up data of this patient population are urgently required for further evaluation of the different treatment options.

Another aspect of CABG surgery in HTX recipients is the increasing shortage of suitable donor organs, leading to the ex- tension of donor criteria. In this situation, there is the tendency toward accepting donor organs with known or suspected coronary artery disease. ${ }^{21,22} \mathrm{~A}$ simultaneous CABG procedure can be performed in these patients; however, long-term results of this approach are lacking. Among our patients, 4 accidentally received an allograft with pre-existing coronary artery disease, as described above. They underwent successful surgical revascularization, indicating that the aforementioned extension of donor criteria might, in fact, be justified.

\section{Valve Surgery}

TR is the most common valvular disease after HTX. ${ }^{8}$ Owing to structural defects of the tricuspid valve, repair has been performed in only 4 of 19 patients in our study group. As we ${ }^{9}$ have shown before, tricuspid valve replacement seems to be superior to reconstruction after HTX. There are several reports on treatment options in TR after HTX that are summarized in Table 4. Filsoufi and associates ${ }^{13}$ report on 8 patients who had tricuspid valve surgery after HTX. Six of them were primarily treated with tricuspid valve repair. However, in 3 of them repair failed and secondary valve replacement was necessary. Alharethi and coworkers ${ }^{12}$ share our preference for tricuspid valve replacement versus tricuspid valve repair in this patient group because of the underlying structural leaflet defects. 
TABLE 3. Literature review: CABG surgery after HTX*

\begin{tabular}{|c|c|c|c|c|c|}
\hline & Patients/ procedures (n) & $\begin{array}{c}\text { Interval between HTX and } \\
\text { surgery, mo (range) }\end{array}$ & Kind of surgery (n) & Deaths early/late (n) & $\begin{array}{l}\text { Follow-up, } \\
\text { mo (range) }\end{array}$ \\
\hline Halle $1995^{3}$ & $12 / 12$ & $57 \pm 20$ & $\begin{array}{c}10 \mathrm{CABG} \\
1 \mathrm{CABG}+\mathrm{AVR} \\
1 \mathrm{CABG}+\mathrm{TVR}\end{array}$ & $4 / 1$ & $9 \pm 7$ \\
\hline Patel $1997^{4}$ & $6 / 6$ & $54 \pm 13(24-89)$ & $\begin{array}{c}5 \mathrm{CABG} \\
1 \mathrm{CABG}+\mathrm{TMLR}\end{array}$ & $3 / 2$ & $23 \dagger(2-64) \dagger$ \\
\hline Musci $1999^{5}$ & $7 / 7$ & $67(6-128)$ & $\begin{array}{c}6 \mathrm{CABG} \\
1 \mathrm{CABG}+\mathrm{TVR}\end{array}$ & $3 / 0$ & $10(2-32)$ \\
\hline Rothenburger $2005^{6}$ & $7 / 7$ & $58(26-114)$ & 7 CABG & $0 / 2$ & $?$ \\
\hline Bhama $2009^{7}$ & $13 / 14$ & $147 \pm 75(15-251)$ & $14 \mathrm{CABG}$ & $0 / 3$ & $39 \pm 36(0.3-110)$ \\
\hline Goerler & $17 / 19$ & $108 \pm 65(1-212)$ & $19 \mathrm{CABG} \pm$ & $0 / 11$ & $69 \pm 44(3-142)$ \\
\hline
\end{tabular}

Wong and coworkers ${ }^{8}$ summarize their review about the treatment of TR after HTX as follows: tricuspid valve repair should be considered in cases of dilated tricuspid annulus; however, a bioprosthetic valve replacement is preferred in leaflet prolapse and biopsy-induced chordal injury. However, the actual aim must be the prevention of TR, which is ultimately achieved by the appropriate implantation technique. All but 1 patient who required tricuspid valve surgery after HTX at our institution underwent transplantation before 2000. Until then, orthotopic HTX was performed by the technique described by Lower and Shumway. ${ }^{23}$ Currently, the bicaval implantation technique is used in all patients, except for small children. As the Cleveland group has shown, the bicaval implantation technique was associated not only with a significantly reduced incidence of TR, and thereby significantly better preserved cardiac function, but also with a significantly improved survival after trans- plantation. ${ }^{24}$ Another preventive strategy in the context of TR is the reduction in endomyocardial biopsies. Several studies have reported an association between the frequency of endomyocardial biopsies and TR. ${ }^{8}$ Therefore, and owing to the improvement of echocardiography, the number of routine myocardial biopsies has been significantly reduced at our institution. Preventive strategies also include tricuspid valve annuloplasty during HTX as described by the Philadephia group. ${ }^{25}$ They found a perioperative mortality advantage in the group with prophylactic DeVega tricuspid valve annuloplasty. Long-term cardiac mortality was reduced in that group as well. On the basis of their results, they recommend tricuspid valve annuloplasty as a routine adjunct to orthotopic HTX. However, although significant TR develops in a significant number of patients late after HTX, as $w^{26}$ have reported previously, surgery is required in only a small minority of symptomatic patients. ${ }^{8,10,25}$

TABLE 4. Literature review: Tricuspid valve surgery after HTX*

\begin{tabular}{|c|c|c|c|c|c|}
\hline & $\begin{array}{l}\text { Patients/procedures } \\
\text { (n) }\end{array}$ & $\begin{array}{c}\text { Interval between HTX } \\
\text { and surgery, mo (range) }\end{array}$ & Kind of surgery (n) & Deaths early/late (n) & $\begin{array}{l}\text { Follow-up, } \\
\text { mo (range) }\end{array}$ \\
\hline Wahlers $1996^{9}$ & $12 / 12$ & $70 \pm 32 \dagger$ & $\begin{array}{c}8 \text { TVR } 4 \text { TV repair } \\
(+1 \text { CABG })\end{array}$ & $0 / 2$ & $?(3-21) \ddagger$ \\
\hline Yankah $2000^{10}$ & $17 / 18$ & $105(2-161)$ & $\begin{array}{c}11 \text { TVR } \\
7 \text { TV repair } \\
(+2 \text { CABG; }+8 \text { other proc. })\end{array}$ & $1 / 5$ & $30(4-81)$ \\
\hline Chan $2001^{11}$ & $6 / 6$ & $?$ & 6 TVR & $0 / 0$ & $13 \pm 7(6-24)$ \\
\hline Alharethi $2006^{12}$ & $17 / 18$ & $77 \pm 48$ & $\begin{array}{l}16 \text { TVR } \\
2 \text { TV repair }\end{array}$ & $1 / 1$ & $33 \pm 50(0-154)$ \\
\hline Filsoufi $2006^{13}$ & $8 / 11$ & $21 \S(2-84)$ & $\begin{array}{l}5 \text { TVR } \\
6 \text { TV repair }\end{array}$ & 2 & 55 (TVR) 72 (TV repair) \\
\hline Musci $2007^{14}$ & $19 / 19$ & $78(2-180)$ & $\begin{array}{l}12 \text { TVR } \\
7 \text { TV repair } \\
(+3 \text { CABG })\end{array}$ & $3 / 4$ & $35(0-97)$ \\
\hline Goerler & $19 / 20$ & $103 \pm 50(2-200)$ & $\begin{array}{l}16 \mathrm{TVR} \| \\
4 \mathrm{TV} \text { repair } \\
(+2 \mathrm{CABG})\end{array}$ & $1 / 10$ & $77 \pm 66(1-200)$ \\
\hline
\end{tabular}

HTX, Heart transplantation; $T V R$, tricuspid valve replacement; $T V$, tricuspid valve; $C A B G$, coronary artery bypass grafting. *Included were only studies with more than 5 patients. $\dagger$ †alculated from available data. ŁSurvivors. §Only first surgical procedure. $\|$ One patient after aortic valve replacement and mitral valve replacement is not included. 


\section{Acute Aortic Dissection Type A}

In our study population, acute aortic dissection type A occurred in 3 patients at different times after transplantation. In all patients, the dissection was limited to the donor part of the aorta below the suture line, which prevented further extension of the dissection. A common risk profile of these patients was not identified. Obviously, the limitation of the dissection to the donor part of the aorta is not mandatory. Rothenburger and colleagues ${ }^{6}$ presented the cases of 2 patients with acute aortic dissection requiring combined ascending aorta and aortic arch replacement; one of them survived the procedure. Both dissections occurred during the fifth year after transplantation. Another patient with type $\mathrm{B}$ dissection underwent endovascular stent implantation. Knosalla and associates ${ }^{27}$ summarized their experience with HTX in 10 patients with Marfan syndrome. Among them, 2 patients underwent replacement of the thoracoabdominal aorta for chronic dissection, 14 and 20 months after transplantation, and both patients survived. Another patient died 4 years after HTX owing to ruptured aortic dissection type B. In summary, acute aortic dissection can be successfully treated in HTX recipients.

\section{Limitations of the Study}

Although this is a large cohort of patients with a long follow-up as compared with other studies reported in literature, the overall number of patients remains low. To this point, differences between the 2 groups might be missed, as well as risk factors for mortality. Owing to the retrospective character of the study, echocardiographic assessment of ventricular function was incomplete, especially in patients of the early era. Therefore, ejection fraction has not been included in the analysis of risk factors.

\section{CONCLUSION}

According to these results, we consider nonretransplant surgical options for CAV and valvular disease a safe and effective therapeutic approach with acceptable long-term results. Although the definitive treatment option for all kinds of cardiac allograft failure remains cardiac retransplantation, nonretransplant surgical options have to be considered as first-line therapy whenever possible, owing to the scarcity of suitable donor organs and associated short-term mortality.

\section{References}

1. Taylor DO, Edwards LB, Boucek MM, Trulock EP, Waltz DA, Keck BM, et al. International Society for Heart and Lung Transplantation. Registry of the International Society for Heart and Lung Transplantation: Twenty-fourth official adult heart transplantation report-2007. J Heart Lung Transplant. 2007;26:769-81.

2. Mehra MR. Contemporary concepts in prevention and treatment of cardiac allograft vasculopathy. Am J Transplant. 2006;6:1248-56.

3. Halle AA 3rd, DiSciascio G, Massin EK, Wilson RF, Johnson MR, Sullivan HJ, et al. Coronary angioplasty, atherectomy and bypass surgery in cardiac transplant recipients. J Am Coll Cardiol. 1995;26:120-8.
4. Patel VS, Radovancevic B, Springer W, Frazier OH, Massin E, Benrey J, et al. Revascularization procedures in patients with transplant coronary artery disease. Eur J Cardiothorac Surg. 1997;11:895-901.

5. Musci M, Pasic M, Meyer R, Loebe M, Wellnhofer E, Weng Y, et al. Coronary artery bypass grafting after orthotopic heart transplantation. Eur J Cardiothorac Surg. 1999;16:163-8.

6. Rothenburger M, Hülsken G, Stypmann J, Wichter T, Tjan TD, Löher A, et al. Cardiothoracic surgery after heart and heart-lung transplantation. Thorac Cardiovasc Surg. 2005;53:85-92.

7. Bhama JK, Nguyen DQ, Scolieri S, Teuteberg JJ, Toyoda Y, Kormos RL, et al. Surgical revascularization for cardiac allograft vasculopathy: is it still an option? J Thorac Cardiovasc Surg. 2009;137:1488-92.

8. Wong RC, Abrahams Z, Hanna M, Pangrace J, Gonzalez-Stawinski G, Starling R, et al. Tricuspid regurgitation after cardiac transplantation: an old problem revisited. J Heart Lung Transplant. 2008;27:247-52.

9. Wahlers T, Albes J, Pethig K, Oppelt P, Fieguth HG, Jurmann M, et al. Valve reconstruction or replacement for long-term biopsy-induced tricuspid regurgitation following heart transplantation. Transplant Int. 1996;9:S247-8.

10. Yankah AC, Musci M, Weng Y, Loebe M, Zurbruegg HR, Siniawski H, et al. Tricuspid valve dysfunction and surgery after orthotopic cardiac transplantation. Eur J Cardiothorac Surg. 2000;17:343-8.

11. Chan MC, Giannetti N, Kato T, Kornbluth M, Oyer P, Valantine HA, et al. Severe tricuspid regurgitation after heart transplantation. J Heart Lung Transplant. 2001; 20:709-17.

12. Alharethi R, Bader F, Kfoury AG, Hammond ME, Karwande SV, Gilbert EM, et al. Tricuspid valve replacement after cardiac transplantation. J Heart Lung Transplant. 2006;25:48-52.

13. Filsoufi F, Salzberg SP, Anderson CA, Couper GS, Cohn LH, Adams DH. Optimal surgical management of severe tricuspid regurgitation in cardiac transplant patients. J Heart Lung Transplant. 2006;25:289-93.

14. Musci M, Yankah CA, Klose H, Baretti R, Weng Y, Meyer R, et al. Heart valve operations in solid organ recipients: an 18-year single-center experience. Transplantation. 2007;84:592-7.

15. Goerler H, Simon A, Gohrbandt B, Hagl C, Oppelt P, Haverich A, et al. Cardiac retransplantation: is it justified in times of critical donor organ shortage? Longterm single-center experience. Eur J Cardiothorac Surg. 2008;34:1185-90.

16. Johnson MR, Aaronson KD, Canter CE, Kirklin JK, Mancini DM, Mehra MR et al. Heart retransplantation. Am J Transplant. 2007;7:2075-81.

17. Smits JM, Vanhaecke J, Haverich A, de Vries E, Roels L, Persijn G, et al. Waiting for a thoracic transplant in Eurotransplant. Transplant Int. 2006;19:54-66.

18. David TE, Feindel CM. An aortic valve-sparing operation for patients with aortic incompetence and aneurysm of the ascending aorta. J Thorac Cardiovasc Surg. 1992;103:617-21.

19. Onorati F, Presta P, Fuiano G, Mastroroberto P, Comi N, Pezzo F, et al. A randomized trial of pulsatile perfusion using an intra-aortic balloon pump versus nonpulsatile perfusion on short-term changes in kidney function during cardiopulmonary bypass during myocardial reperfusion. Am J Kidney Dis. 2007;50:229-38.

20. Tatoulis J, Buxton BF, Fuller JA, Royse AG. Total arterial coronary revascularization: techniques and results in 3,220 patients. Ann Thorac Surg. 1999;68: 2093-9.

21. Koyanagi T, Minami K, Tenderich G, Reiss N, Morshius M, Mirow N, et al. Thoracic and cardiovascular interventions after orthotopic heart transplantation. Ann Thorac Surg. 1999;67:1350-4.

22. Laks H, Gates RN, Ardehali A, Capouya ER, Moriguchi JD, Kobashigawa JA, et al. Orthotopic heart transplantation and concurrent coronary bypass. J Heart Lung Transplant. 1993;12:810-5.

23. Lower RR, Shumway NE. Studies on the orthotopic homotransplantations of the canine heart. Surg Forum. 1960;11:8.

24. Sun JP, Niu J, Banbury MK, Zhou L, Taylor DO, Starling RC, et al. Influence of different implantation techniques on long-term survival after orthotopic heart transplantation: an echocardiographic study. J Heart Lung Transplant. 2007;26: 1243-8.

25. Jeevanandam V, Russell H, Mather P, Furukawa S, Anderson A, Raman J. Donor tricuspid annuloplasty during orthotopic heart transplantation: long-term results of a prospective controlled study. Ann Thorac Surg. 2006;82:2089-95.

26. Wilhelmi M, Pethig K, Wilhelmi M, Nguyen H, Strüber M, Haverich A. Heart transplantation: echocardiographic assessment of morphology and function after more than 10 years of follow-up. Ann Thorac Surg. 2002;74:1075-9.

27. Knosalla C, Weng YG, Hammerschmidt R, Pasic M, Schmitt-Knosalla I, Grauhan $\mathrm{O}$, et al. Orthotopic heart transplantation in patients with Marfan syndrome. Ann Thorac Surg. 2007;83:1691-5. 